\title{
Rhesus monkey (Macaca mulatta) cool sensitivity measured by a signal detection method
}

\author{
HELEN H. MOLINARI, ANDREW J. RÓZSA, and DAN R. KENSHALO \\ Florida State University, Tallahassee, Florida 32306
}

\begin{abstract}
Two rhesus monkeys were trained to detect cool stimuli (decrements in skin temperature from the adapted temperature) presented to the palm of the left hand after the skin had been preadapted to a $33^{\circ} \mathrm{C}$ temperature. The procedure was analogous to the signal detection "yes-no" method used with human observers. Receiver operating characteristic curves were generated by varying the a priori probability of stimulus occurrence. The proportion of hits and of false alarms increased with increases in the a priori probability of stimulation. The points of isosensitivity of both subjects for cool intensities of $0.3^{\circ} \mathrm{C}$, but not at greater intensities, yielded straight lines with slopes of approximately one when plotted on normal-normal coordinates. The values of the $d_{s}^{\prime}$ detectability index decreased from 3.52 to 0.75 for one subject and from 2.81 to 1.28 for the other as the stimulus intensity was decreased from $0.8^{\circ}$ to $0.15^{\circ} \mathrm{C}$ cooling from the adapting temperature. Cool thresholds for each subject of $0.19^{\circ}$ and $0.12^{\circ} \mathrm{C}$ were computed from classical psychometric functions when threshold was defined as $50 \%$ hits at a $50 \%$ probability of stimulus oceurrence. These thresholds are comparable to published reports of the cool threshold for the rhesus.
\end{abstract}

It has been shown that both rhesus and guenon monkeys are able to discriminate between two hand-operated levers that differ in temperature by $1{ }^{\circ} \mathrm{C}$ (Cragg \& Downer, 1967; Laursen, 1972; Porter \& Semmes. 1974). These observations have been extended by measuring thresholds of warm and cool stimuli applied to the shaved skin of the inner thigh of the rhesus after the skin had been adapted to temperatures between $28^{\circ}$ and $40^{\circ} \mathrm{C}$ (Kenshalo \& Hall, 1974). Thresholds at these adapting temperatures were measured by the conditioned suppression method (Smith, 1970). Thresholds for warm stimuli decreased from $0.5^{\circ}$ to $0.02^{\circ} \mathrm{C}$, while those for cool stimuli increased from $0.05^{\circ}$ to $0.28^{\circ} \mathrm{C}$, as the adapting temperature was increased from $28^{\circ}$ to $40^{\circ} \mathrm{C}$. Compared to humans, on which thresholds were measured by the method of limits (Kenshalo, 1970). the rhesus monkeys were more sensitive to changes in temperature at all but the $40^{\circ} \mathrm{C}$ adapting temperature.

However, cross-species, cross-methods comparisons are tenuous, at best. They assume similarities in the experimenter's definition of threshold. the subject's definition of threshold. and the subject's motivation and response biases. If the rhesus temperature sensing system is to serve as a model for that of humans, then similarities and differences must be specified much more precisely than is possible with the methods employed to date.

Signal detection theory (SDT) provides a method,

This research was supported by NSF Grant GB-30610. We would like to thank Dr. Karen J. Berkley for her critical review and comments on the manuscript. Reprints may be obtained from Dan R. Kenshalo. Department of Psychology. Florida State Lniversity. Tallahassee. Florida 32306. applicable to both human and infrahuman species. whereby a measure of stimulus detectability ( $\left.d^{\prime}\right)$ is obtained that is independent of motivational and criterion biases. The response biases of the subjects can also be evaluated (Egan \& Clarke, 1966).

The only studies we have found that have employed SDT in the measurement of temperature detectability have used human subjects (Cain, 1973; Clark \& Mehl. 1971. 1973; Stevens, Okulicz, \& Marks, 1973; Vendrik \& Eijkman, 1968). The present study was undertaken to evaluate the applicability of SDT in measuring the detection of thermal stimuli by infrahuman species.

\section{METHOD}

\begin{abstract}
Subjects
The subjects were two feral rhesus monkeys (Macaca mulatta). one male (M1) and one female (M2), weighing approximately $3 \mathrm{~kg}$ at the start of the experiment. Daily feeding sessions, about $1 / 2 \mathrm{~h}$ in length. occurred in their home cages within $2 \mathrm{~h}$ after the experimental session. During this period, the subjects were given free access to food and a restricted amount of water. The daily fluid intake consisted of 75 to $100 \mathrm{ml}$ of apple juice earned during the experimental session and only enough water during the feeding period to bring the total to $200 \mathrm{ml}$.
\end{abstract}

\footnotetext{
Apparato:

Just prior to the experimental session, the subject was led from his home cage and seated in a Foringer monkey chair (Figure 1). The chair was then wheeled into an Industrial Acoustics Company sound-attenuating chamber for the experimental session. A liquid dispenser. which delivered $0.64 \mathrm{ml}$ of apple juice per operation. was attached to the chair within easy reach of the subject's mouth. A cue light panel was mounted in front of the subject at eye level. and a spring-loaded sliding bar was within easy reach of the subject's right hand. About $1.0 \mathrm{~cm}$ of movement of the bar toward the subject closed an electrical contact. After the electrical contact wis closed. another $3.0 \mathrm{~cm}$ of movement was possible. The subject's left
} 


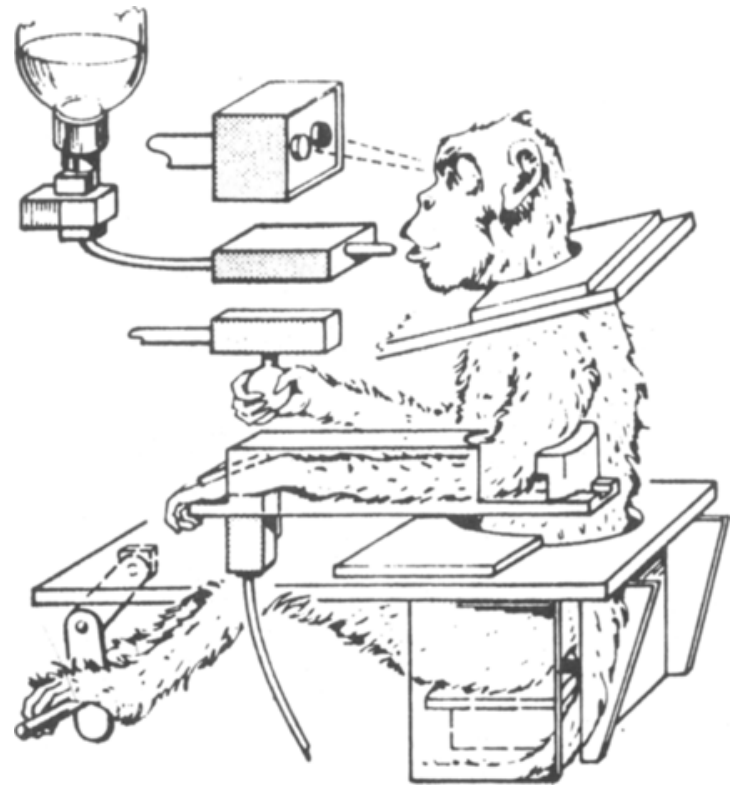

Figure 1. Testing apparatus. The subject is seated in the chair with hips and neck restrained. The left forearm is restrained in a Plexiglas arm holder that holds the thermal stimulator against the palm of the left hand. A spring-loaded sliding bar is within reach of the right hand. A cue light panel is located at eye level. Apple juice is delivered to the subject through a solenoid and a drink tube.

forearm was restrained in a Plexiglas arm holder. The arm holder contained the thermal stimulator and held it in constant contact with the palm of the subject's hand.

The thermal stimulator, which covered an area of $7.2 \mathrm{sq} \mathrm{cm}$ of the palm, operated on the Peltier principle. Its temperature control depended upon the amount and polarity of direct current passed through the unit (Kenshalo \& Bergen, 1975). The stimulator maintained any temperature within the physiological range with an accuracy of $\pm 0.001^{\circ} \mathrm{C}$. This was established by observing that the voltage analog of the skin temperature at the skin-stimulator interface did not vary by more than $\pm 1 \mathrm{mV}$ (the thermistor bridge amplifier was calibrated to deliver $1 \mathrm{~V}^{\circ} \mathrm{C}$ ). During the calibration period, the stimulator was held in contact with the palmar skin of a human seated in a quiet room. Changes in the temperature of the stimulator from $0.01^{\circ}$ to $5^{\circ} \mathrm{C}$ at rates up to $2{ }^{\circ} \mathrm{C} / \mathrm{sec}$ were obtained with an accuracy of $1 \%$. The rate and intensity of a temperature change were independent. Because operation of the thermal stimulator was entirely electrical, cues to respond, other than the temperature changes, did not occur. For convenience, decrements in stimulator temperature from an adapted temperature are referred to as "cool" stimuli, and increments as "warm" stimuli. Thus, a cool stimulus of $1^{\circ} \mathrm{C}$ when presented from a maintained temperature of $33^{\circ} \mathrm{C}$ represents a change to an absolute temperature of $32^{\circ} \mathrm{C}$.

A PDP. 8 computer programmed the experimental paradigm and recorded events. A PDP-12 computer was used in the data analysis.

\section{Procedure}

A single-interval, yes-no procedure was used. The more expeditious rating procedure can be applied to animal studies through the analysis of response rates (Blough, 1967) or latencies (Kulics. Carlson, \& Werner, 1974; Yager \& Duncan, 1971). But the yes-no procedure is the procedure of choice in evaluating the shape of the ROC curves (Egan \& Clarke, 1966).

Trial structure. The subject initiated a trial by pulling the lever. A trial was divided in to three consecutive periods. each of $3 \mathrm{sec}$ duration: the prestimulus, stimulus, and poststimulus periods. During the stimulus period, a cool stimulus, with a maximum duration of $3 \mathrm{sec}$, was presented or not according to one of the a priori probabilities. The lever pull also lighted a green cue light to indicate that a trial was in progress. The green light remained on until the subject released the lever or until the $3-\mathrm{sec}$ stimulus period ended, whichever came first.

A response consisted of a lever release at some time after trial initiation. A lever release during the 3 -sec prestimulus period constituted an anticipatory response, which resulted in a 15-sec time-out. During all time-outs, a white cue light was lighted and lever pulls were ineffective. At the end of the $15 \mathrm{sec}$, the white light was terminated and the subject was again able to injtiate a trial. Anticipatory responses occurred rarely during data collection.

Two types of response, hits and misses, were possib?e on trials in which a cool stimulus was presented. A lever release during the stimulus period was scored as a hit, and the subject received $0.64 \mathrm{ml}$ of apple juice reinforcer. Failure to release the lever during the stimulus period was scored as a miss and resulted in a 15-sec time-out which commenced at the end of the stimulus period.

Two types of response. false alarms and correct rejections, were possible on trials in which a cool stimulus was not presented. A lever release during the stimulus period was scored as a false alarm and resulted in a 15 -sec time-out. A lever release during the poststimulus period was scored as a correct rejection, and the subject received the apple juice reinforcer. A lever release after the end of the poststimulus period (late release) was without consequences. Late releases rarely occurred in data collection sessions

Training. The subjects were led from their individual home cages by collar and chain and were trained to seat themselves in the restraint chair (Hurst \& Lucero, Note 1). They cooperated to the extent that they inserted the left forearm and hand into the thermal stimulator restraint device.

The subjects were trained to pull and release the lever in order to receive apple juice. They then learned to hold the lever through the 3-sec prestimulus period and to release the lever when a red light was lighted during the stimulus period. The occurrence of the red light was paired with a $5^{\circ} \mathrm{C} \mathrm{cool} \mathrm{stimulus} \mathrm{of} \mathrm{up} \mathrm{to} 3 \mathrm{sec}$ duration. Cooling occurred at a rate of $2^{\circ} \mathrm{C} / \mathrm{sec}$ from the $33^{\circ} \mathrm{C}$ adapting temperature. A lever release at any time during the stimulus period turned off the red light, returned the thermal stimulator to the $33^{\circ} \mathrm{C}$ adapting temperature, and delivered apple juice to the subject. The green light was then introduced along with reinforcement for correct rejections. The probability of stimulus occurrence was reduced from 1.0 to 0.5 . The time-outs were also introduced at this time.

Once the subject had attained a correct response rate above $95 \%$, the red light was gradually dimmed. The intensity of the cool stimulus that was paired with the red light remained constant. The rate of fading of the red light was determined by the degree of stimulus control exhibited by the subject during the daily sessions. Although the subjects learned to respond to the red light within a month, it took several months of daily training of both subjects to transfer control to the cool stimulus alone. Once this control was established, the intensity and rate of the cool stimulus were gradually reduced to $0.8^{\circ} \mathrm{C}$ cooling at a rate of $1^{\circ} \mathrm{C} / \mathrm{sec}$.

Experimental variables. The stimulus variables were the intensity of the cool stimulus and the probability of stimulus presentation, $\mathrm{p}(\mathrm{S})$. The $\mathrm{p}(\mathrm{S}) \mathrm{s}$ used were $0.25,0.50$, and 0.75 . Cool intensities of $0.8^{\circ}, 0.5^{\circ}, 0.3^{\circ}, 0.2^{\circ}$, and $0.15^{\circ}$ were used for both $\mathrm{M} 1$ and $\mathrm{M} 2$. In addition, $\mathrm{M} 1$ was tested at $0.18^{\circ} \mathrm{C}$ and $\mathrm{M} 2$ was tested at $0.13^{\circ}$, $0.10^{\circ}$, and $0.08^{\circ} \mathrm{C}$.

Response variables were the proportion of hits, $p($ HIT), and of false alarms, $p$ (FA). ROC curves (i.e., isosensitivity curves) were generated for the $0.8^{\circ}, 0.5^{\circ}$, and $0.3^{\circ} \mathrm{C}$ cool stimuli by varying the $\mathrm{p}(\mathrm{S})$. For the remaining intensities, $\mathrm{p}(\mathrm{S})$ equaled 0.50 .

Experimental sewions. The subject, seated in the restraint chair with the left forearm restrained in the stimulator holder, was placed in the sound-attenuating chamber. The thermal stimulator control 


\section{Z-SCORE OF FALSE ALARMS}
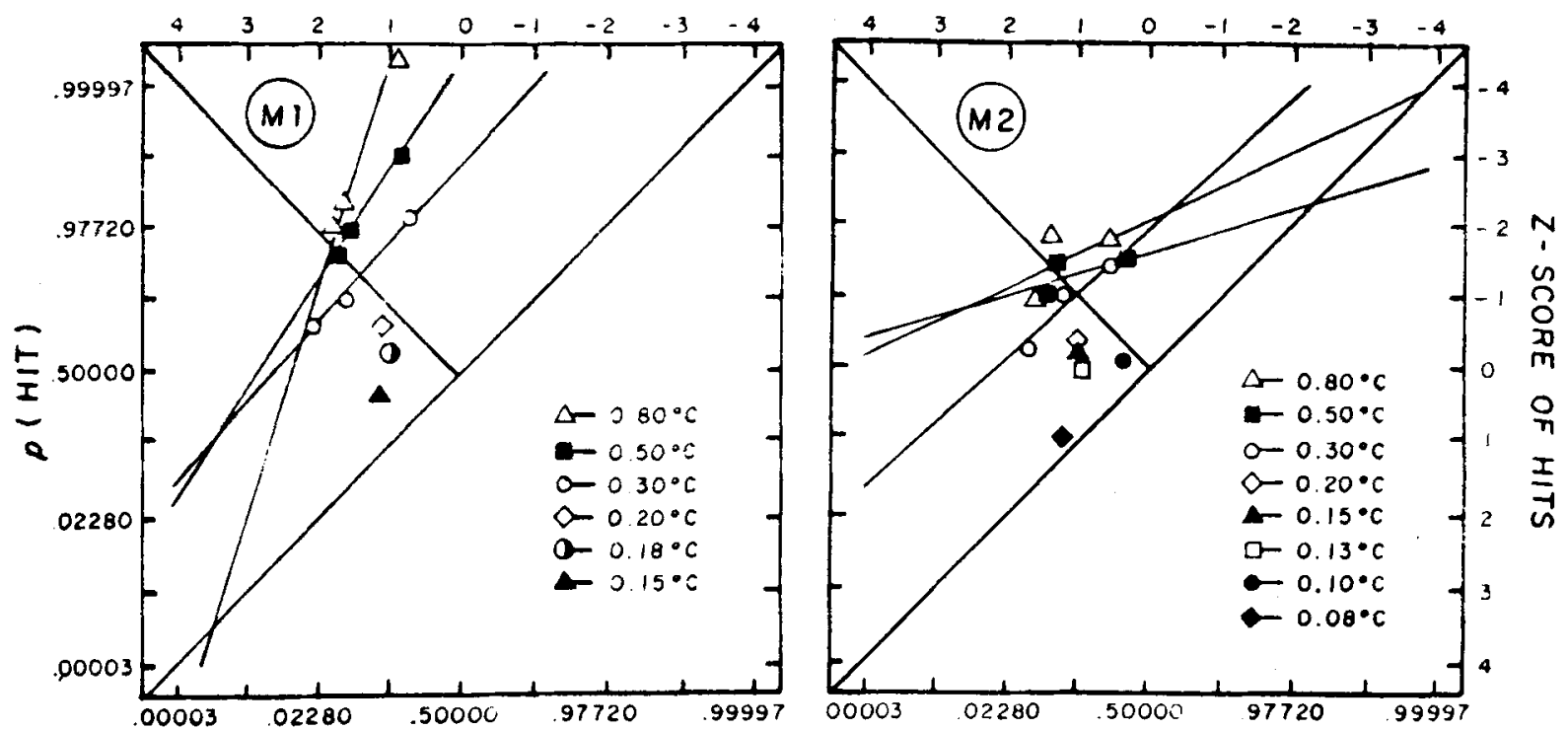

p (FA)

Figure 2. Receiver operating characteristics for subjects $\mathrm{M} 1$ and $\mathrm{M} 2$ for detecting a number of cool intensities (at $1^{\circ} \mathrm{C} / \mathrm{sec}$ ) from a $33^{\circ} \mathrm{C}$ adapting temperature. The symbol $\mathrm{p}(\mathrm{HIT})$ stands for the proportion of hits, and $\mathrm{p}(\mathrm{FA})$, for the proportion of false alarms.

apparatus was set to maintain the palmar skin at $33^{\circ} \mathrm{C}$. the adapting temperature. After the subject had adapted for $10 \mathrm{~min}$. the session began. Sessions were held 6 days a week.

Infrahuman species act as "minimally informed observers" and can only act on the basis of a posteriori information. Through training and experience with each probability factor, the animal's perforninace can be expected to approach that of the informed subject (Boneau \& Cole. 1967). To this end. practice sessions of 200 trials each day were given after each change in the stimulus intersity or in the $\mathrm{p}(\mathrm{S})$ until the $\mathrm{p}(\mathrm{HIT})$ and $\mathrm{p}(\mathrm{FA})$ were stable (less than $10 \%$ fluctuation) for 3 consecutive days. Data collection for each point on the ROC curves consisted of five daily sessions of 200 trials each. Thus, each point on the ROC curves represents the $\mathrm{p}(\mathrm{HIT})$ and $\mathrm{p}(\mathrm{FA})$ during 1,000 trials. Stimulus intensities were presented in descending order and $\mathrm{p}(S) \mathrm{s}$ in a sequence of 0.50 .0 .25 , and 0.75 at each intensity down to and including the $0.3^{\circ} \mathrm{C}$ intensity.

We assumed that once the ROC curves, plotted on normal-normal coordinates. became linear and their slopes approached one. those at lesser intensities would also be linear with slopes of approximately one. This assumption is based on the observation that the slopes of ROC curves often are not equal to one at high intensities of stimulation but approach unity at lower intensities and remain stable thereafter (Cain, 1973; Green \& Swets. 1974). Another factor influencing this decision was the large number of daily sessions (often up to 25 at the low intensities of stimulation) required to achieve stable responding and data collection for each point. With unit slopes. only one point is needed to determine the location of the ROC curves (Green \& Swets. 1974). Consequently, lower stimulus intensities (below $0.3^{\circ} \mathrm{C}$ ) were tested only at $\mathrm{p}(\mathrm{S})$ equal to 0.50 .

Data analysis. The ROC curves were computed by plotting the $z$ scores of $p(H I T)$ and of $p(F A)$ and computing a least squares regression line that fit the three data points at stimulus intensities of $0.3^{\circ} \mathrm{C}$ and higher. While a least squares fit is at best only an approximation, it is considered to be adequate for the present purposes (Pastore \& Scheirer, 1974). An estimator of the $d$ detectability index. $d_{s}^{\prime}$, was determined for each ROC curve following Pastore and Scheirer. At the lower stimulus intensities. for which only one value of $\mathrm{p}(\mathrm{S})$ was used. the value of the detectability index was determined directly from the $z$ scores of the point (Green \& Swets. 1974).

\section{RESULTS}

The $\mathrm{p}(\mathrm{HIT})$ and $\mathrm{p}(\mathrm{FA})$ made in 1.000 trials for each $\mathrm{p}(\mathrm{S})$ at each stimulus intensity are shown in Figure 2. Each point represents the criterion used by the subject in responding to a particular stimulus intensity at a particular $\mathrm{p}(\mathrm{S})$. The ROC curves for the $0.8^{\circ}, 0.5^{\circ}$, and $0.3^{\circ} \mathrm{C}$ stimulus intensities are shown as the line of best fit connecting the three response criteria. The response criteria for $\mathrm{M} 1$ fell close to the line of best fit. Those for M2 deviated from the line of best fit at the $0.8^{\circ} \mathrm{C}$ cool intensity, but the deviations decreased as stimulus intensity decreased.

The slopes of the ROC curves for both subjects deviated from one at the high stimulus intensities but approached one as the stimulus intensity was decreased. The slopes for $M 1$ decreased from 2.85 to 1.13 and those for $\mathrm{M} 2$ increased from 0.3 to 0.9 for stimulus intensities of $0.8^{\circ}$ to $0.3^{\circ} \mathrm{C}$.

The $p(H I T)$ and $p(F A)$ are shown as a function of $p(S)$ in Figure 3, using the same data as plotted in Figure 2. As can be seen, the subjects changed their response criteria by decreasing $\mathrm{p}(\mathrm{HIT})$ and $\mathrm{p}(\mathrm{FA})$ at each of the three stimulus intensities as the $p(S)$ decreased. The response criteria at the $p(S)$ of 0.5 for both subjects fell above the minor diagonal for the $0.8^{\circ}$ and $0.5^{\circ} \mathrm{C}$ stimulus intensities, indicating a bias 


\section{Z-SCORE OF FALSE ALARMS}
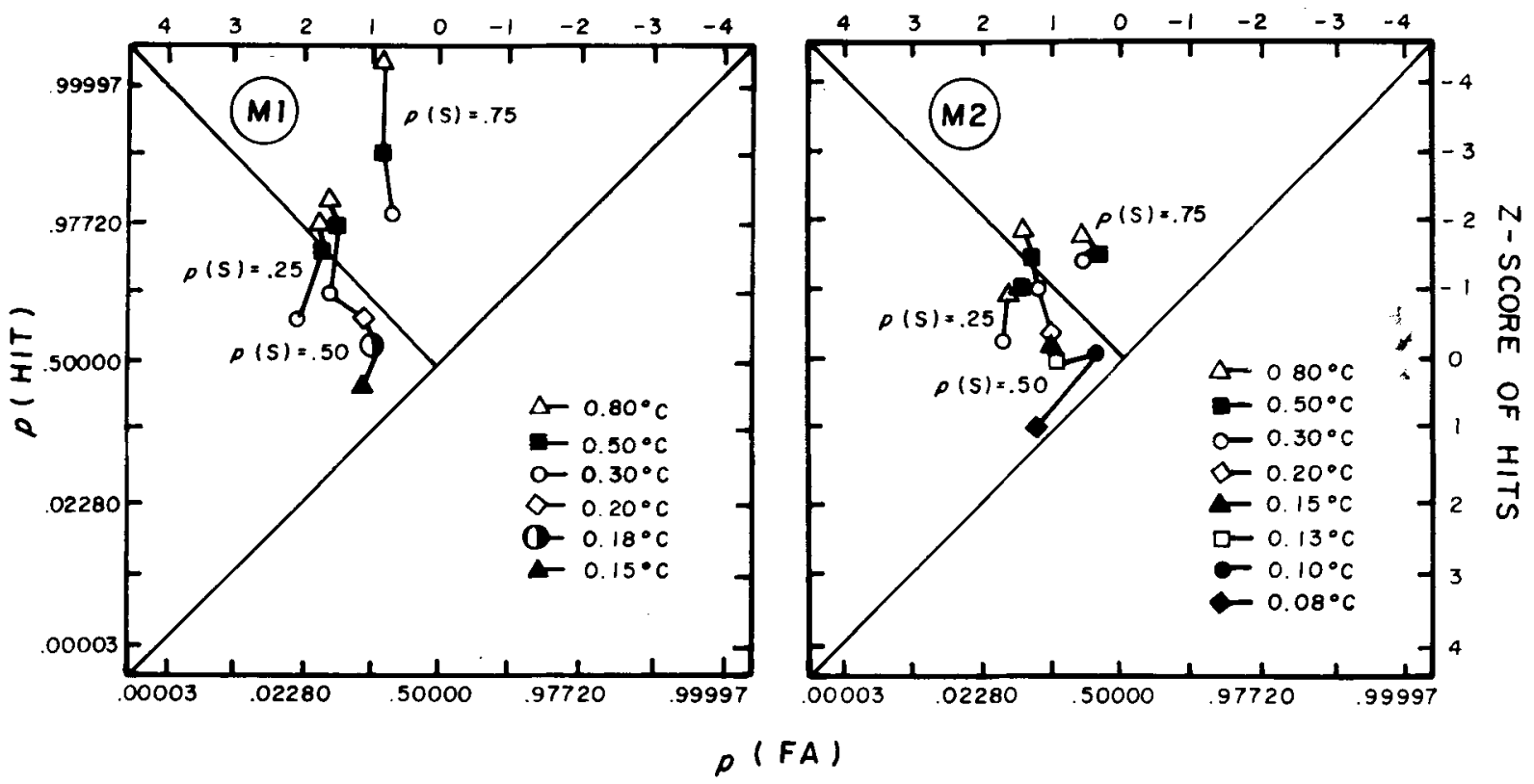

Figure 3. Response criteria for subjects $M 1$ and $M 2$ as a function of probability of stimulus occurrence, $p(S)$, for a number of cool intensities (at $1^{\circ} \mathrm{C} / \mathrm{sec}$ ) from a $33^{\circ} \mathrm{C}$ adapting temperature.

toward making "yes" responses. As the discrimination became more difficult. the criteria fell below the minor diagonal, indicating a bias shift toward "no" responses.

The $d_{s}^{\prime}$ values are plotted as a function of stimulus intensity in Figure 4. As the stimulus intensity decreased, the $d_{s}^{\prime}$ values for each subject decreased in a similar manner. The relationship between $d_{s}^{\prime}$ and stimulus intensity approached linearity for intensities of $0.3^{\circ} \mathrm{C}$ and below. At higher, more easily detected stimulus intensities, the relationship became curvilinear. A similar type of curve was found by Terman (1970) to describe the relationship of $d^{\prime}$ to auditory stimulus intensity for rats.

A classical psychometric function may be derived from these data by plotting the $\mathrm{p}(\mathrm{HIT})$ at a $\mathrm{p}(\mathrm{S})$ of 0.50 as a function of stimulus intensity (Figure 5). Threshold was defined as the stimulus intensity at which $\mathrm{p}(\mathrm{HIT})$ equaled 0.50 . Subject $\mathrm{M} 1$ had a threshold of $0.19^{\circ} \mathrm{C}$ and $\mathrm{M} 2.0 .12^{\circ} \mathrm{C}$ for cooling from the $33^{\circ} \mathrm{C}$ adapting temperature.

\section{DISCUSSION}

The subjects shifted their response criteria at each stimulus intensity as the probability of stimulus occurrence was altered. The criteria approximated linear ROC curves. indicating that sensitivity remained constant at a given intensity. Reliable estimates of the slopes of the ROC curves for the easily discriminable stimulus intensities (i.e., $0.5^{\circ}$ and $0.8^{\circ} \mathrm{C}$ ) are difficult to obtain (Green \& Swets. 1974).
For instance, an increase of only $3 \%$ in the p(HIT) made by $\mathrm{M} 1$ at $\mathrm{p}(\mathrm{S})$ equal to 0.75 for $0.8^{\circ} \mathrm{C}$ over $0.5^{\circ} \mathrm{C}$ (from 0.96 to 0.99 , Figure 2) drastically altered the placement of that point and, thus, the slope of the line. The slopes of the ROC curves for the $0.3^{\circ} \mathrm{C}$ cooling stimulus were close to one, as would be predicted by SDT (Green \& Swets, 1974).

The subject shifted from a "yes" to a "no" response bias as stimulus intensity decreased at $p(S)$ equal to

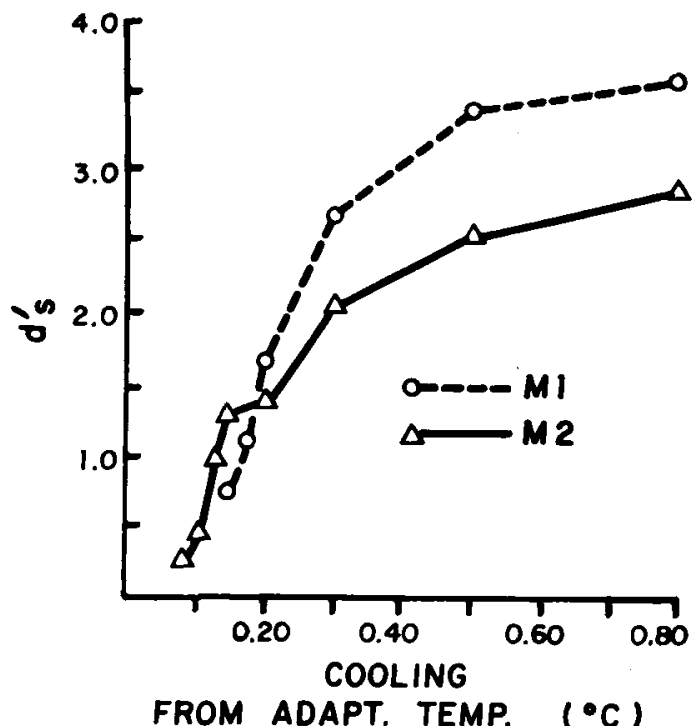

Figure 4. The values of $d_{s}^{\prime}$ detectability index as a function of cooling stimulus intensity (at $1^{\circ} \mathrm{C} / \mathrm{sec}$ ) from a $33^{\circ} \mathrm{C}$ adapting temperature for subjects $\mathrm{M} 1(0)$ and $\mathrm{M} 2(\Delta)$. 


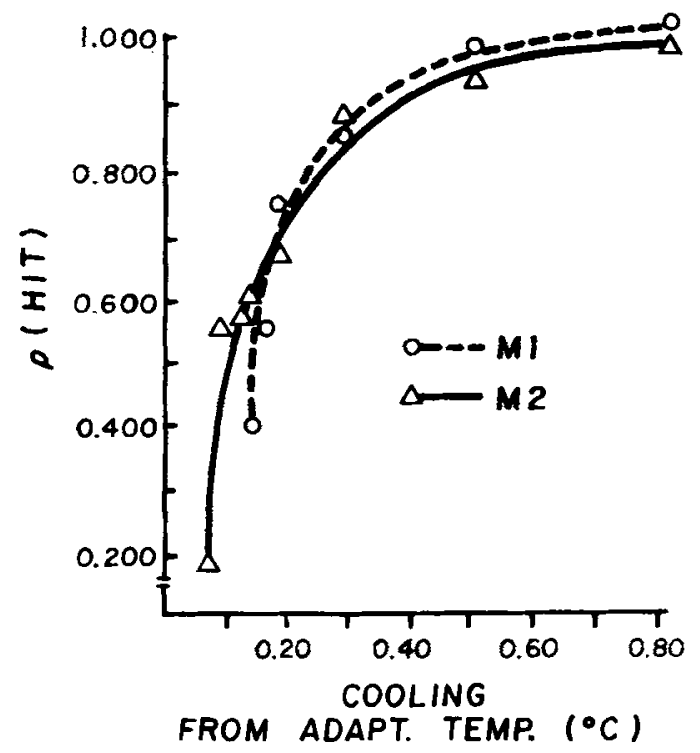

Figure 5. The proportion of hits, p(HIT), as a function of cooling stimulus intensity (at $1^{\circ} \mathrm{C} / \mathrm{sec}$ ) from a $33^{\circ} \mathrm{C}$ adapting temperature at an a priori probability of stimulation equal to 0.50 for subjects M1 (0) and M2 ( $\Delta)$.

0.5. Although the payoff matrix was asymmetric (time-outs for misses occurred automatically, but time-outs for false alarms only followed lever releases), it was constant throughout testing and therefore could not have produced the bias shift. If the 3-sec interstimulus interval were not sufficient to allow readaptation, a "no" bias would be expected. In fact. a "yes" bias occurred at the largest stimulus intensities, where failure to readapt would have the greatest effect. Rather, it appears that the bias shift resulted from the subjects' responding to the decrease in stimulus intensity as though it were a decrease in probability of stimulation. With human subjects, informed that the a priori probability does not change as stimulus intensity is decreased, one would not expect to find these bias shifts.

The cool thresholds determined for the two subjects in this study were $0.19^{\circ}$ and $0.12^{\circ} \mathrm{C}$. Kenshalo and Hall (1974) used a conditioned suppression technique and found that the mean threshold for the rhesus (as determined from Figure 3 of Kenshalo and Hall, 1974) for cooling $7.2 \mathrm{sq} \mathrm{cm}$ of the thigh from a $33^{\circ} \mathrm{C}$ adapting temperature was $0.07^{\circ} \mathrm{C}$. Comparisons of thermal thresholds across studies where different techniques are used and different body areas tested (Stevens, Marks, \& Simonson, 1974) are difficult. But, given these considerations, the agreement between thresholds is considered to be good.

In this study, the subjects' ability to detect a stimulus was measured by $\mathrm{d}_{\mathrm{s}}^{\prime}$. In every instance, the values of $d_{s}^{\prime}$ for both subjects decreased with decreases in stimulus intensity. Therefore, these values provide a reasonable measure of stimulus detectability.
The amount of effort and time involved in obtaining estimates of signal detectability in monkeys by this SDT method is large compared to that involved in other behavioral methods (Stebbins, 1970). Had our interest been solely the temperature sensitivity of rhesus, another method would have been used. However, our interest was to use a method that could be employed equally with rhesus and humans in order to provide comparable measurcments of thermal sensitivity so that cross-species comparisons could be direct. The SDT methods are the only formal methods that we are aware of that can be used equally well on human and infrahuman species and which provide, in addition to a measure of sensory acuity, a measure that allows assessment of response bias.

\section{REFERENCE NOTE}

1. Hurst, C. M., \& Lucero, J. R. A collar and chain procedure for handling and seating Macaca mulatta. Technical Report ARL-TR-66-14, 651st Aeromedial Research Laboratory, Holloman Air Force Base, New Mexico, 1966.

\section{REFERENCES}

Blougr, D. S. Stimulus generalization as signal detection in pigeons. Science, $1967,158,940-941$.

Boneau, C. A., \& Cole, J. L. Decision theory, the pigeon, and the psychophysical function. Psychological Review, 1967, 74, 123-135.

CAIN, W. S. Spatial discrimination of cutaneous warmth. American Journal of Psychology, 1973, 86, 169-182.

Clark, W. C., \& MEHL, L. Thermal pain: A sensory decision theory analysis of the effect of age and sex on $d^{\prime}$, various response criteria, and $50 \%$ pain threshold. Joumal of Abnormal Psychology, 1971, 78, 202-212.

Clark, W. C.. \& MEHL. L. Signal detection theory procedures are not equivalent when thermal stimuli are judged. Journal of Experimental Psychology, 1973, 97, 148-153.

CRAGG, B. G., \& Downer, J. De C. Behavioral evidence for cortical involvement in the manual temperature discrimination in monkey. Experimental Neurology, 1967, 19, 433-442.

Egan, J. P., \& Clarke, F. R. Psychophysics and signal detection. In J. D. Sidowski (Ed.), Experimental methods and instrumentation in psychology. New York: McGraw-Hill, 196. Pp. 211-246.

GREEN, D. M., \& Swers, J. A. Signal detection theory and psychophysics. New York: Krieger, 1974.

Kenshalo. D. R. Psychophysical studies of temperature sensitivity. In W. D. Neff (Ed.), Contributions to sensory physiology: New York: Academic Press, 1970. Pp. 19-74.

Kenshalo, D. R., \& Bergen, D. C. A device to measure cutaneous temperature sensitivity in human and subhuman species. Journal of Applied Physiology, 1975, 39, 1038-1040.

Kenstialo. D. R., \& Hacl, E. C. Thermal thresholds of the rhesus monkey (Macaca mulatta). Journal of Comparative and Physiological Psychology, 1974, 86, 902-910.

Kulics, A. T., Carlson, K. R., \& Werner, G. Signal detection of stimulus discrimination in normal and split-brain monkeys. Brain Research, 1974, 81, 119-132.

LAURSEN, A. M. Thermal thresholds in man and monkey. Experimental Neurology, 1972, 34, 25-32.

Pastore, R. E., \& Scheirer, C. J. Signal detection theory: Considerations for general application. Psychological Bulletin. 1974, 81, 945-958.

Porter, L., \& Semmes, J. Preservation of cutaneous temperature sensitivity after ablation of sensory cortex in monkeys. Experimental Neurology, 1974, 42, 206-219. 
Smitr. J. C. Conditioned suppression as an animal psychophisical technique. In W. C. Stebbins (Ed.). Animal prichophisics. Nen York: Appleton-Century-Crofts. 1970. Pp. 125-154.

STEBarvs. W. C. (Ed.l. Animal psychophysics. New York: Appleton.Centur. Crotis. $19^{-0} 0$.

Stevens. J. C.. Marks. L. E.. \& Simonson. D. C. Regional sensitivity and spatial summation in the warmth sense. Perception \& Psuchophysics. 1974, 13. 825-836.

Stevens. J. C., Oxulicz, W. C., \& Marks. L. E. Temporal summation at the warmth threshold. Perception \& Psichophisics. 19-3. 14, 307.312.
TERMAN. M. Discrimination of auditory intensities by rats. Journal of Experimental Analysis of Behavior, 1970, 13. 145-160. Vendrik. A. J. H., \& Eijkman, E. G. Psychophysical properties determined with internal noise. In D. R. Kenshalo (Ed.). The skin senses. Springfield. III: Thomas. 1968. Pp. 178-192.

YAGER. D. \& DUNCAN, I. Signal detection analysis of luminance generalization in goldfish using latency as a graded response measure. Perception \& Psychophysics, 1971, 9, 353-355.

(Received for publication August 11, 1975; revision accepted October 6, 1975.) 